\section{A PLEA FOR THE EARLY RECOGNITION AND TREATMENT OF PUERPERAL FEVER. ${ }^{1}$}

BY JOHN W. BYERS, M.A., M.D. R.U.I.,

PROFESSOR OF MIDWIFERY, QUJEN'S COLLECIE, BSLLAST'.

I THINK we are all now agreed that puerperal fever is a preventable disease, and that the measures we should adort to prevent its occurrence are very much the same as those used by the surgeon to aroid the onset of what was formerly called surgical fever, but which we know now to be sepsis. In our ideal obstetric practice we aim at having an aseptic patient, nurse, and medical attendant, and all our precautions, such as keeping the external parts of the parturient, our own hands, as well as those of the nurse, and all obstetric instruments and appliances aseptic, the greater employment of external examination, the limitation of vaginal touch only to acquire information which cannot be obtained by abdominal palpation, the not allowing the labour to be too prolonged, and the inmediate suturing of any wounded parts, - I say all these precautions are taken with the object of preventing sepsis. One other preventive measure let me strongly urge, and that is a careful attempt on the part of the obstetrician to note in every pregnant woman any abnormal condition of the blood, such as hydræmia or anæmia, and to make an effort to correct this before the onset of labour. We know the part micro-organisms play in the causation of sepsis, but we have not yet thoroughly discovered why a lying-in woman seems to be so susceptible to their action. Perhaps it may be the condition of her blood or of her excreting organs at all events, any abnormality in her condition should be noted before her confinement and carefully corrected. In this way her power of resistance to the action of microbic poisons may be strengthened. Unfortanately at times, notwithstanding all these efforts, our technique at some point breaks down and as a result we are called upon to encounter one of the most unfortunate, and too often fatal, conditions we can meet in practice. Cases of puerperal infection seem to be more common now in private than in hospital practice; the reverse was formerly the case. One explanation of this fact is probably because in maternities the most rigid antiseptic and aseptic practice is now in force, and also, I believe, because cases going wrong are recognised earlier and treated more promptly. There is also another cause too often met with in private practice, and that is the existence still of many murses who do not know, who do not believe in, and who do not employ, modern antiseptic precautions. Cases of puerperal infection are, as we all know, most fatal, but I am firmly impressed with the belief that when the condition is recognised early and treated promptly many women might be rescued who are otherwise lost. In no condition is early treatment of greater importance than in puerperal infection.

What, then, are the early symptoms of puerperal infection and what lines of treatment should we employ when these symptoms appear? The early symptoms of puerperal infection are elevation of temperature and quickness of pulse, but this question of temperature and pulse raises two other important points : first, what is the effect of the lying-in period on these phenomena? and second, may the pulse be quickened and the temperature be raised during the lying-in yeriod from conditions other than puerperal infection?

1. I am fully convinced that where aseptic and antiseptic precautions are complete the pulse and temperature during the lying-in period differ little from what they would be in the non-puerperal condition. We sometimes find that, especially in a primipara, there may be some elevation of temperature, $99^{\circ} \mathrm{F}$. or occasionally $100^{\circ}$ during the first day, due to the braising and laceration of the soft parts, and I can corroborate the interesting observations of Dr. ProbynWilliams and Mr. Lennard Cutler ${ }^{2}$ that the average temperature of primaparæ both on the morning and evening of the first day and in the morning of the second is higher than in multiparæ. On the evening of the second day the temperatures in each class of cases are the same, and remain, as a rule, identical afterwards. If the perineum is carefully

1 A paper read in the section of Obstetric Medicine at the meeting of the British Medical Association at Carlisle, July, 1896.

2 Transactions of the Obstetrical Society, vol. xxxvii., p. 19, \&c. sutured and the parts are kept aseptic I have found the temperature differ very slightly from the normal. A temperature above $99^{\circ}$, except in the first day, should always put the accoucheur on his guard that something septic may be brewing. As to the pulse, notwithstanding what is taught in many text-books that there is a marked slowing in the pulse after delivery, my experience has been that its rate is rarely below seventy and is more often from seventyfive to eighty in the minute. I have also noted the curious fact recorded by Dr. Probyn-Williams and Mr. Cutler that during the lying-in period the pulse-rate is a little quicker when taken in the morning than in the evening. I have also observed the rate of the pulse quickened in some cases of forceps delivery where chloroform was used (from 100 to 110 or 120), and remain so for twelve, eighteen, or twentyfour hours without any ill effects. In nervous, highly-strung women of the upper classes the same quickness of pulse often occurs for a day or two after delivery. In both these types of cases the quick pulse differs altogether from the rapid pulse met with in postpartum hæmorrhage in that the beats do not run into one another, they are distinct, with an appreciable interval, and there is evident vascular tension.

2. May the pulse be quickened and the temperature be raised during the lying-in period from conditions other than puerperal infection? I am sure every obstetrician of experience has come across cases in which he has felt for a time very uneasy about his recently-delivered patient from fever having set in with quick pulse, and yet the subsequent progress of the case has shown that there was nothing septic in the condition. Broadly speaking, we are kept right in our diagnosis in such cases by the following points : (a) there are usually no special pelvic or abdominal symptoms ; $(b)$ the lochia are normal; $(c)$ the secretion of milk continues; $(d)$ carefal examination enables us to discover some complicating disease present at an early period, which in itself is sufficient to account for the patient's state; and $(e)$ the history of the case and the patient's previous medical condition help in diagnosis.

Here are very brief details of some cases from my notebooks in which, during the lying-in period, there were fever and quick pulse not depending on sepsis.

1. Tonsilltitis. - I was asked to see the wife of a medical man who, on the third day after delivery, had a shiver, followed by a temperature of $103^{\circ} \mathrm{F}$, and a pulse of 120 . She complained of sore-throat, and this culminated in a sharp attack of tonsillitis, a disease she was very subject to. No other pathological condition dereloped, and when the abscess in the tonsil opened she became convalescent. The local signs appearing early and her previous tendency to quinsy put sepsis out of the question and quickly relieved her husband's mind.

2. Appendicitis.-A patient who had been under the late Mr. Arthur Durham's care in London with an attack of appendicitis was attended by me at her first confinement. Three days after the birth of the child she became feverish from a recurrent attack of the same complaint, which, with rest and treatment, gradually subsided. For a time it looked like a commencing septic case. The previous history and early appearance of the former local trouble were the points in the diagnosis.

3. Influenza.-During the late influenza epidemic women during the puerperium were often attacked, the condition in some cases simulating puerperal septic infection. I saw one most puzzling case where a patient became sharply ill with high fever on the fourth day after delivery. When I examined her with her medical attendent on the sixth the temperature was $104^{\circ} \mathrm{F}$., the pulse 130 , and she was perspiring profusely, and looked as if attacked with acute septicæmia. A few days afterwards her condition decidedly improved, and at the same time other members of her household were seized with symptoms of influenza, thus establishing the diagnosis. In another case a patient in the eighth month was taken with influenza (others of the same family being ill), followed by premature labour, with fall of pulse and temperature, and on the third day after delivery she was seized with a rigor accompanied with renewal of fever, which culminated in pneumonia, from which she recovered.

4. Pelvic abscess.-A woman had her cervix divided for dysmenorrhoea, the operation being followed by a feverish attack, which passed off, leaving the patient subject to attacks of right-sided pelvic pain. After a premature (first) confinement she was seized with high fever and a swelling developed in the right posterior quarter of the pelvis, which 
suppurated and suddenly emptied itself per rectum, after which the patient made a good recovery.

5. Rheumatism.-I have seen cases in which this disease set in after delivery and in which at first the condition was very like septic infection, the subsequent progress of the patient settling the question of diagnosis.

6. Suppurating ovarian tumours.-I have seen in consultation two cases in which fever in the puerperium was caused by suppurating ovarian tumours, which I removed successfully by abdominal section, the patients both making good recoveries.

7. Phthisis. - I have also attended cases where high fever early in the lying-in period was occasioned by the rapid development of tuberculosis which for a time simulated septic poisoning.

It is said by some observers that constipation may occasionally give rise during the puerperal period to fever which is due to the absorption of ptomaines, and that a free action of the bowels lowers the temperature by sweeping away these poisons. I have not seen such cases, and with strict aseptic and antiseptic precautions I doubt if they really occur. I think, then, if we exclude conditions such as I have mentioned, and which, after all, are not very common, we are warranted in concluding that it is on the whole rare to have fever and quick pulse in the first five or six days after labour from any other cause than infection, and in my own experience the earlier the symptoms of puerperal infection appear after labour the severer will be the course of the disease and the graver the prognosis. The very worst cases are those which go wrong soon after delivery. If a patient gets a week over normally she may still become intected, but if so the disease will likely become local and there will be an absence of grave constitutional disturbarce. It is during the first few days after delivery that, in the language of bacteriologists, the body is apt to prove so favourable a culture ground for micro-organisms, the explanation of this being the presence of fresh wounds, the lochia, and the bare placental area. There are two kinds of infective disease which may be met with in the early stage of the lying-in perion-sapræmia and septicæmia.

1. In sapræmia the system is infected by a chemical poison due to the action of micro-organisms on dead decomposing matter, such as the lochial discharge, pieces of placenta, membrane, \&c. The poison does not multiply in the blood, but really outside the body at the seat of a wound, as, for example, the placental area, or wound in the parturient canal, and its effects depend on the amount of the poison absorbed. If we remove the dead decomposing matter in which the microbes are acting, and if the dose already taken up is not a fatal one, the chances are the patient will recover.

2. In septicamia. on the contrary, the symptoms are from the growth and multiplicatiun of the micro-organisms in the blood which they have reached through a wound. They can enter through the smallest wound, and there seems to be no relation between the extent of the wounds received in parturition and the amount of the lochial discharge and the tendency to septicæma. The fact that the poison is being constantly produced insids the body makes the disease so serious.

While, from a pathological and etiological point of view, these two conditions are so distinct, yet cliuically, in the early stage, the diagnosis between them is difficult, nay, even at times impossible, as the symptoms at first are the same in both, and the problem is still more complicated by the fact that they of ten occur together-that, is the patient is the subject of a mixed infection. Oue thing, however, is clear, it is the alteration in the pulse and temperature duriug the lying.in period which tells us our patient is not in a normal state, and it is of the utmost impurtance that a correct record be made of these two phenomena night and morning durir $g$ the first five or six day: after delivery, so that we may at once be put on the alest in ca e the patient gets infected. Let me suppose (to make the matrer practical) that a patient on the third or fourth day after delivery, with or without an initial rignr, has a temperature of $103^{\circ}$ or $104^{\circ}$ and a pulse of fr.m 120 to 130 , and that there are no signs of any of those conditions present which occasionally occur during the putrperium, and the diagnosis of which I have discussed, our wise plan is to assume that she is infected. We must not let the nurse or patient put us off our guard by saying the breasts are the disturbing element or that she has "only a chill"; we must not be led into error because the abdomen is soft or because the luchia are su eet and have not ceased to flow. In nine out of ten cases the rise of temperature and quickness of pulse indicate she is infected, and if we $2 \mathrm{na}$ at once she may be rescued. Precious time is often lost in simply giving antipyrin, quinine, alcohol, or diaphoretics, and at the next visit the patient may have had anothe: shiver, the abdomen may be tendex or slightly swollen, and she may be beyond chance of treatment. I would therefore strongly urge that when fever with quick pulse sets in we should at once begin local treatment. Even though the symptoms, as may afterwards turn out to be the ease, are due to other conditions than puerperal infection, the loca? treatment can do no harm, and in the vast majosity of cases the rise of pulse and temperature shows the patient is infected. Before commencing treatment a thorough examina. tion of the patient must be made in the following order the pelvic floor (perineum, \&c.), vagina, and uterus; and it is to be noted that wounds at the lower part of the parturient canal are very serious from the circumstance that, being near the outer world, organisms enter easily. As a rule, now, tears of the perineum are sutured at once. When this is not done they are at times very liable to become septic. I have seen cases of puerperal infection where the wounds of the pelvic floor bave been corered with a diphtheritic deposit, and at other times both the torn perineal edges black and gangrenous. When these wounds are seen to be unhealtby they should be washed with a 1 in 1000 corrosive sublimate solution, euretted $d_{r}$ or touched with the actual cautery or with nitrate of silver solution (sixty grains to the ounce), and then dusted with iodoform. Aloscess of Bartolini's gland should be freely opened, cauterised, and packed with iodoform gauze. Septic and diphtheritis: vaginitis, if present, should be thoroughly treated in the same way as the septic or diphtheritic conditions of the pelvic floor. The utelus must then be erplored, and it is to be remembered that in the great majority of ases puerperal infecion emanates from it. The septic virus mas have enteled through its lymphatiss or the patient may hare become infected through a decomposing mass lying in its cavity. Certain types of women are apt to berome in. fected: (1) the anæmic, and (2) those who, owing to premature rupture of the membranes, have had a long and tedious first stage. In the prophy lactis management of such cases the most rigid aseptic and antiseptic precautions must be taken.

In the local treatment of the uterus we hare the choice of three methods: (1) simple irrigation; (2) sontinuous irriga tion; and (3) curettage. The plan to be adopted will depend on the condition ascertained by a digital examination. If the finger finds the cervix markedly patslous, and if on exploring the interior of the uterus one feels any foreign mass (often putrid and foul-smelling), or if there is the sensation of a soft tissue which on pressing with the internal finger seems to break down, then ever, at this early stage the uterus should be carefully curetted, the indications for this operation at this periud being, fœtur still persisting after douching the vagina, a patulous cervix and the detection of some: decomposing body in the uterine cavity. On the other hand, if the endometrium feels nurmal (that is, if there seems to be no soft tissue breaking down) simple in rigation is called. for, with certain precautions in its techniqae. 1. The graritation douche, not the syringe, should be wsed. 3. The intra-aterine tube should be large in order that a good fust may remove any clots, remains of nuembranes, dźbris, \&cc. It should be passed up to the fundus, and I have found it $a$ ustful plan to seize the arteriur lip of the cervix with a vulsella so as to steady the uterus and render its cavity straight. In this way the douche-tube is more easily passed up to the top of the cavity of the uttrus and every parts flushed. I prefer for the first douche to u:e a 1 in 4000 corrosive sublimate solution unless the patient has renal disease: or has suffered from postpaltum lomorrbage, when some other antiseptic shouid be tmuploytd, as creolin, lysol, on iodine ; it is to be noted, as has betn pointed out by WatsonCheyne, ${ }^{3}$ that these antiseptic solutiows, if too strong, act deleteriously on tisi bes already weakened by cuntacts with poisonous products, and thus by causing their death may afford more pabulum for the putrefactive. micro-organisms; beuce, too, towerful antiseptics should not be employed. 4 In doaching out the uterus. plenty of fluid should be used; instead of one or twc, vints from eight to $t \in \mathrm{n}$ should be employed. and the temperature of the fluid should be $100^{\circ}$ to $105^{\circ} \mathrm{F}$., as in 
this way the parts will not be injured and owing to the heat the douche will have a stimulating effect. 5 . In douching care should be taken to see and to examine any membrane, piece of débris, \&c., which may come away. If after this simple irrigation of the uterine cavity the temperature falls suddenly or gradually, the pulse at the same time becoming slower, it need not be repeated. On the other hand, if, after irrigating the uterus, the temperature remains unaffected, or if after a fall it rises the next day, I would advise the douche to be used again, and if it brings down the temperature and pulse the case may take a favourable turn. Suppose, however, notwithstanding the repetition of the simple irrigation, the temperature remains unaffected or even rises, and the patient has further rigors, then we must use one of two methods-either continuous irrigation or the curette. Professor Pinard of Paris is a strong advocate for continuous irrigation, which he recommends if the temperature remaius high on the evening of the third day. He thinks the continuous irrigation of advantage, even if afterwards it is decided to curette the uterus, as it renders the endometrium as aseptic as possible, and the rise of temperature and shivering, which I have often seen follow curetting, are either absent or less marked, according to Professor Pinard, if douching has been previously used. The continuous irrigation may be employed for as long as twelve hours or more. Weak carbolic lotion, lysol, or boracic acid may be used as the antiseptic in such conditions. This continuous irrigation has, I think, not received sufficient trial in English obstetric practice; in many cases it has a wonderful effect, and from the Amsterdam clinic Huinereck ${ }^{4}$ reports fifty-two cases of puerperal sepsis treated by prolonged irrigation with $1,1 \frac{1}{2}$, or 2 per cent. carbolic acid or a 1 in 4000 corrosive sublimate solution; following this irrigation the inner surface of the uterus was painted with undiluted tincture of iodine; all those treated in this way recovered, the treatment being begun as soon as the fever dereloped. It may be objected to irrigation of the uterus that (1) the mere surface of the endometrium is affected, hence the organisms on the surface alone are rendered inert, while those deeper in the tissues are not acted upon; (2) repeated douching is often painful and entails considerable disturbance of a patient who is already weak and nervous; and (3) such repeated manipulations may really run the risk of conveying more septic infection. On the other hand, the practical results after this method of treatment are, I know, most evident in many cases ; and, according to Professor Pinard, it favours the subsequent use of the curette. There is a type of case occasionally met in which irrigation is of great value, and that is when, owing to the decomposition of a syphllitic fotus, the woman becomes infected before delivery. Here douching out the uterus after labour has begun before dilating the cervix is good practice, and the same method can be used if after delivery the temperature keeps up or if after a fall it again rises. If, however, in spite of this continuous irrigation the patient's condition does not improve I would adrocate the curetting of the uterus, an operation which from frequent favourable experience in such cases I can strongly recommend, and if the patient is no better on the fourth day it should then be employed, the rationale of its action being that the curette remores any decomposing material and the lining membrane of the uterus in which the bacilli find a suitable culture medium for their growth. If carefully done, $I$ have seen no harm accruing in the use of the curette in the postpartum uterus; sometimes the operation may be followed by shivering or slight hamorrhage, but if the uterus is packed with iodoform gauze (which $I$ think is the best plan) the risk of bleeding is anticipated. I remove the gauze in twenty-four hours, and if after this the temperature again rises I would re-curette, as the chances are there is something still which needs to be removed from the uterine cavity. It will be seen I recommend curettage to be done early in infected cases only under certain conditions which I have mentioned, but as a rule it is better not to employ the curette until irrigation has been first tried. If the uterus is curetted on the fourth day of the patient's illness it has this adrantage in its favour, that the necrosing endometrium is beginning to separate. On the other hand, if examination on the first day of a patient's illness shows that the uterus is empty curetting will really do harm, as the morbid process may be purely local on the surface of the mucous membrane and the use of the curctte will he bad, as we may in this way open up channels by which fresh infection may spread. In cases in which irrigation and curettage fail the only other measure we can try is the serum treatment-that is, the injection of the anti-streptococcus serum; but up to the present this plan has not been very successful. At the very interesting discussion which took place at the Obstetrical Society of France in April, 1896, Dr. Charpentier, reporting on cases treated by anti-streptococcus serum, was compelled to admit that the treatment had not so far fulfilled the expeotations raised when it was first introduced. Dr. Roux and Dr. Marmorek state that the anti-streptococcus serum can have no effect if, simultaneously with its administration, one continues the use of intra-uterine treatment (injections, swabbing, curettage, \&c.), and Dr. Marmorek advised medical men who ask for anti-streptococcus serum to abstain from any other form of treatment, suggestions against which several of those taking part in this discussion strongly protested, Dr. Budin saying he could not understand why they should be told to renounce cleansing the uterus in cases of infection by irrigation, swabbing, and curettage in favour of a very doubtful measure which promises well for the future, but offers little security for the present.

At the present time the whole question of sero-therapy in the treatment of puerperal infection is still in an experimental stage. It may be the treatment of the future. We want, however, more information as to the action of the serum and the class of cases to which it is suitable. No doubt we may soon acquire this and the carefully recorded case of "Acute hæmorrhagic septicæmia treated by antistreptococcus serum" by Mr. Ballance and Mr. Abbott, with the additional note on the preparation of anti-streptococcus serum by $\mathrm{Mr}$. Bokenham, 5 is of the greatest importance in showing what sero-therapy will do in a bad case of septicæmia. Quite recently another method of sero-therapy in the treatment of puerperal septicamia was brought before the Paris Academy of Medicine on June 30th, 1896, by Professor Pozzi, who read a report on a paper by Professor Duret of Lille on this subject. This method, which is suitable alike to septicæmia following operations as well as in the puerperium, is specially recommended in desperate cases when death is imminent, and consists in intravenous, followed up by bypodermic, injections of sterilised water containing chloride of

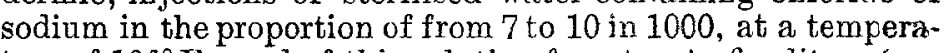
ture of $104^{\circ} \mathrm{F}$, and of this solution from two to five litres (say three to five pints) may be injected in the twenty-four hours. The rationale of this treatment is that, in the first place, by raising the intra-vascular pressure it increases the patient's power of resistance, enabling her to carry on the struggle against the disease. In cases of septicremia the bloodmaking organs thus get time to produce new bloodcorpuscles for phagocytosis, and the kidneys, the secretion of which is increased, eliminate the toxines. Care should be taken to see the kidneys are in good working order before resorting to this rnethod of treatment. While I have had experience of the great value of saline injection in cases of severe bromorrhage I have not yet tried its use in puerperal septicæmia. It will, however, be well worth employing, as Pozzi advises, in desperate cases. While thus strongly advocating local treatment in puerperal infection I would also recommend that every effort should be made to keep up the patient's strength hy the administra. tion of concentrated nutritious food in a liquid form, quinine, digitalis, strychnine, and alcohol. Of abdominal bysterectomy, as practised by some of our American cunjrères in puerperal fever, I have no personal knowledge, but when there is any localised mischief in the abdomen surgical interference is, I know from experience, of the greatest value.

Let me say, in conclusion, on every onc of us engaged in obstetric practice devolves the duty of forestalling and preventing puerperal infection. We have to watch that those who are expecting to be confined shall be in the best possible condition to sustain the exhausting fatigue and risk of childbearing. Our endearour should be to prevent by prophylactic measures the onset of infection, but when, in spite of our efforts, this ensues then, by early recognition of jts occurrence and by prompt treatment, I am more and more convinced that not only may the death-rate be minimised, but that there shall be less liability to subsequent gynæcological disease. This requires, not only experience and 
practical training, but it demands the most unremitting care on the part of the practitioner. I have endeavoured, I know in a very feeble way, to contribute my quota of experience on this most important subject, in the hope that, from the discussion that will follow in this section, we may from the mipe experience of the members present gain more help in the treatment of a condition that has been hitherto so fakel and that is always most worrying and vexatious to the medical attendant.

Belfast.

\section{MENTAL OVERSTRAIN IN EDUCATION. ${ }^{I}$}

BY G. I. SHUTTLEWOR'TH, B A. LoND., M.D., M.R.C.S. ENG., \&C.,

TORMTERLY MEDICAL SUPERINTENDENI OF THHE ROYAT ALBERT ASYLUM, LANCASTER.

IN venturing to make a few remarks upon a somewhat trite subject I must plead as justification the fact that, notwithstanding much that has been said and written in the way of warning by men more experienced than myself, there still exist indications of a tendency to mental overstrain in certain departments of education. In the consideration of the subject it may be well to clear the ground by discussing the questions (1) What is education? and (2) What is meant by edusetional over-pressure, or such pressure in education as is likely to result in mental overstrain? and (3) finally, to inguire into the incidence, the etiology, and the signs of snch over-pressiure. A few words may follow as regards prevention and treatment.

To answer the question, What is education? it may be aseful to consider what it is not. With some so-called oducationalists I fear the idea still lingers that it consists of cramining a mind with as much of as many subjects as possible. Our laughing philosopher Mr. Punch has, however, very truly observed that "you cannot idle grammar, arithmetic, and geography into a child's brain as you would brimstone and treacle into his stomach"; indeed, a smattering of philology will serve to show that the word "education" means not "putting in " but "drawing out." And. bering in mind the physiological intercepentence of bodily and mental development, we may say tivat true education consists in processes of training which will prodace in a given individual the most favourable svolution possible of all the faculties both of body and mind. A rntional educational system will of course recognise the facs that children are not cast in the same mould, that there are inherent--often inherited-differences in each pupil's povers, and that to attain the best results instruction must be adapted to idiosyncrasies and proportioned to varying capacities. Moreover, the comprehensive and far-reaching chivacter of education must be borne in mind, including as it dues-as Paley puts it-" every preparation that is made in our youth for the sequel of our lives." From the medical standpoint, iisdeed, we shall reply in the affirmative to the gnery of Plato, "Is not that the best education which gives to the mind and to the body all the force, all the beanty, tund all the perfection of which they are capable?" Overpressuie in education may in brief be described as a neglect of the principles just set forth-a neglect which cannot fail t. lead to mentil overstrain. Thus a cast-iron code imposing for each year of age a definite standard of acquirement, heedless of the varying capacities of children, could not tail to produce it. A disregard of physical conditions underlying mental evolution and of critical epochs of devel pment (especially in the female sex) affecting capaciny for exertion is another efficient cause. And the undue excitation of the unstable nerre cells of a child of neurotic heredity to such a pitch of activity as might be harmless in a normal child will in the case of the former be apt to constitute overstrain. Over-pressure, indeed, is not an absolute quantity, but has to be estimated in relation to the jersonal fact $r$ in each case. It may, therefore, be defined in terms of educational work as that amount which in a given case is likely to produce excessive strain of the pliysical or mental system, or both.

Vie vass now to the consideration of its incidence. Since 1070 every young Briton has been compelled to submit to

- A papur (taken as) read in the A ction of Psychology, British Medical desusiation annual meeting, July $315,1896$. educational processes of some description or other between the ages of six and thirteen. School attendance is, however, allowed to count towards a grant from the early age of three, and in some schools there are what are called "babies' classes." Formerly the leading idea with regard to these poor juveniles was that the function of school was to teach them to sit still, regardless of the incessant impulse to movement which characterises all healthy young animals. Charles Kingsley long ago satirised the "foolish fathers and mothers who instead of letting their children pick flowers and make dirt-pies, as little children should, kept them always working, working, working ...... till their brains grew big and their bodies grew small and they were all changed into turnips with little but water inside." And in days not far distant we have heard of hydrocephalus as an alleged product of mental overstrain in early years; indeed, it is reasonable to conclude that, where a proclivity to tuberculosis exists, cerebral hyperomia and the stuffy germ-laden atmosphere of certain school-rooms may conduce to tuber. cular meningitis. To-day a more enlightened view obtains as to the treatment of infants; and the Educational Department now officially directs the fostering of "the spontaneous and coöperative activity of such scholars." The musical drill, kindergarten games, varied occupations, and other exercises now so much in vogue in infant schools, are no doubt extremely beneficial, and with sanitary safeguards the infants in our elementary schools are better off than they would be at home. Although precocious children are sometimes injured by being pushed into prominence it is not in the infant schools that we shall of ten meet with instances of overstrain. Nor is there nowadays, I think, so much evidence of over-pressure in elementary schools for boys and girls as was noticed some twelve years ago by our distinguished confrìre, Sir James Crichton Browne. At that time he proved to his own satisfaction (if not to that of the Education Department) that more than one-third of the children attend. ing elementary schools in London suffered from habitual headache (52.3 of the girls and 40.5 of the boys). He argued, moreover, from the increased prevalence of nervous disease in children-and he cited in support of his argument the increase since the passing of the Education Act in the juvenile mortality from encephalitis, from diabetes, from kidney and rheumatic diseases (claiming these affections as "diseases with marked nervous affinities")-and from the frequency with which he had met with chorea, with stammering, and with neuralgia in school children examined, that over-pressure certainly existed in connexion with compulsory education in elementary schools. In those days it would seem to have affected most severely the backward children, classified by Sir James Crichton Browne as either "dull, starved, or delicate," the code requirements of that date conducing to the whipping up as far as possible of all children to definite age standards. Happily grants are no longer made on the percentage of passes in standards arranged according to age, but after examination of the scholars by sample. Her Majesty's Inspectors are also anthorised to ask the teacher to select a few of the best children for examination in the several subjects, so that the tendency now is not so much to press unduly the dull children as to work up the brighter children to a point that shall dazzle the inspector. Unfortunately, bright, precocious children are not unfrequently the offspring of a neurotic stock, and it is just these that are likely to break down under emotional excitement and the pressure of an examination in prospect. From all I have been able to gather from teachers and from the children's hospitals in London it would seem that it is this class that nowadays furnish cases of school headache, of chorea, and other nervous affections, more particularly about the periods of examination. In secondary education the incidence of over-pressure would seem to be more marked in the preparatory schools than in the public and otber schools for senior boys. "This is probably an instance of the "survival of the fittest," and there is much reason to fear that not a few promising boys, approaching the trying epoch of puberty are sacrificed to the Moloch of competitive examination for entrance scholarships. I do not say that in schools for senior boys there is no over-pressure, but in the great public schools and others following their methods the tendency to brain-strain is counteracted by a goodly proportion of outdoor exercise and physical exertion in the way of games. Happily schools of the type of Dr. Blimber's, satirised by Dickens as " a great hothouse in which there was a forcing apparatus constantly at work, and mental green-peas were 